\title{
Skin Manifestations in Diabetic Patients Attending a Diabetic Clinic in the Qassim Region, Saudi Arabia
}

\author{
Muhammad Shahzad $^{\text {a }}$ Ahmad Al Robaee $^{\text {a Hani A. Al Shobaili }}{ }^{\mathrm{a}}$ \\ Abdullateef A. Alzolibani $^{\text {a }}$ Abdullah A. Al Marshood $^{\text {a }}$ Barakat Al Moteri $^{\text {b }}$ \\ a Department of Dermatology, College of Medicine, Qassim University, and ${ }^{b}$ Ministry of Health, Qassim Region, \\ Saudi Arabia
}

\section{Key Words}

Diabetes mellitus · Skin manifestations · Saudi Arabia

\begin{abstract}
Objective: To investigate the prevalence of skin manifestations in diabetic patients attending a diabetic clinic in the Qassim region, Saudi Arabia. Subjects and Methods: A prospective observational study was performed on 320 patients (174 males and 146 females) attending the diabetic clinic. A detailed dermatological examination was carried out by a consultant dermatologist and the cutaneous findings were recorded. Results: The overall prevalence of skin manifestations was $91.2 \%$. Cutaneous lesions were seen in 12 patients (34.3\%) of type 1 diabetes mellitus (DM) and 280 (98.2\%) of type 2 diabetics. There was a statistically significant difference $(p<0.001)$ in skin manifestations between type 1 and type $2 \mathrm{DM}$ patients. For those patients having diabetes of less than 5 years' duration, the incidence of skin manifestations was $80.6 \%$; for those having had diabetes for more than 5 years, the incidence was $98 \%$. This difference was statistically significant $(p<0.001)$. The skin manifestations that had a statistically significant difference $(p<0.05)$ in prevalence between the 2 durational groups were gangrene, diabetic dermopathy, paresthesia, diabetic feet, diabetic bullae and fungal infections. Conclusion: Diabetics had a greater
\end{abstract}

\section{KARGER}

Fax +41613061234

E-Mail karger@karger.ch

www.karger.com
(C) 2011 S. Karger AG, Basel

1011-7571/11/0202-0137\$38.00/0

Accessible online at:

www.karger.com/mpp prevalence of skin manifestations in type 2 than type 1, and as the duration of diabetes increased, the likelihood of developing skin manifestations also increased. Early referral to the dermatologist may help to detect complications of the skin in diabetes at an early stage and may prevent disability caused by these complications.

Copyright $\odot 2011$ S. Karger AG, Basel

\section{Introduction}

Diabetes mellitus (DM) is a clinical syndrome of abnormal carbohydrate metabolism characterized by hyperglycemia resulting from defects in insulin secretion, insulin action or both [1]. It is broadly classified into type 1 and type 2 diabetes. Long-standing diabetes can lead to permanent and irreversible functional changes and damage to cells of the body, thereby leading to various complications, which mainly result from biochemical, structural and functional abnormalities. A causal association between glycemic control and the development and progression of microvascular complications, i.e. (retinopathy, nephropathy and neuropathy) is well established. By virtue of microvascular involvement, any system or organ can be affected, thus the skin is no exception [2-4]. 
Skin manifestations in DM are common and multifold. According to various studies, $30-82 \%$ of persons with DM have some type of cutaneous involvement during the course of their chronic disease $[1,5]$. Findings range from early signs of long-term involvement such as paresthesia over mild discomfort to indications of serious, even life-threatening problems, e.g. gangrene. Type 2 patients more frequently develop cutaneous infections, whereas type 1 patients more often develop autoimmunetype cutaneous lesions such as alopecia areata, vitiligo and lichen planus [6]. Cutaneous manifestations generally appear subsequent to the development of diabetes but may be the first presenting sign, or even precede the diagnosis by many years; the dermatologist may be the first physician to detect hidden diabetes in a patient $[7,8]$.

The objective of this study was to determine the prevalence and type of skin manifestations in diabetic patients attending the diabetic clinic of the referral hospital affiliated with the College of Medicine, Qassim University, Saudi Arabia. In addition, an examination for clinical correlation with DM was made.

\section{Patients and Methods}

This is a prospective observational study performed on diabetic patients reporting to a diabetic clinic of the referral hospital affiliated with the College of Medicine, Qassim University, Saudi Arabia, between October 2008 and June 2009. The study protocol was approved by the ethics committee of the College of Medicine, Qassim University. The criteria of the American Diabetes Association were used to define the diagnoses, i.e. symptoms of diabetes plus a random blood glucose concentration of $\geq 11.1 \mathrm{mmol} / \mathrm{l}$ $(200 \mathrm{mg} / \mathrm{dl})$ or fasting plasma glucose of $\geq 7.0 \mathrm{mmol} / \mathrm{l}(126 \mathrm{mg} / \mathrm{dl})$ or 2-hour plasma glucose of $\geq 11.1 \mathrm{mmol} / \mathrm{l}(200 \mathrm{mg} / \mathrm{dl})$ during an oral glucose tolerance test. A total of 320 patients aged 12-103 years (174 males and 146 females) having either type of diabetes were included in the study. A thorough medical history and physical examination were done in each case. Informed consent was obtained from each patient or the legal guardian after full explanation of the study protocol.

In accordance with the duration of diabetes, patients were categorized into 2 groups: group I - patients having had DM for up to 5 years, and group II - those having had DM for more than 5 years. A consultant dermatologist (S.M.) carried out the detailed dermatological examination of the patients and recorded the $\mathrm{cu}$ taneous findings, which were later categorized based on possible etiopathogenesis.

The data were analyzed using the computer software program SPSS version 16 (Statistical Package for the Social Sciences, version 16). Pearson's $\chi^{2}$ test was applied for categorical data, and the $\mathrm{t}$ test was used to compare the means within groups. $\mathrm{p}<0.05$ was considered statistically significant.

\section{Results}

The demographic data of the patients included in the study are of a heterogeneous group of the population and are given in table 1 . Out of a total of 320 patients, 35 (10.9\%) had type 1 , while $285(89.1 \%)$ had type 2 diabetes. Of the 320 patients, 292 (91.2\%) had skin manifestations; the remaining 28 (8.8\%) did not have any dermatological findings related to diabetes. Cutaneous lesions were seen in 12 patients (34.3\%) with type $1 \mathrm{DM}$ and in 280 (98.2\%) of the type 2 diabetics. There was a statistically significant difference $(\mathrm{p}<0.001)$ in skin manifestations between type 1 and type $2 \mathrm{DM}$ patients. The prevalence of skin manifestations in the 2 duration groups was $80.6 \%$ in group I and $98 \%$ in group II. This difference was also statistically significant ( $\mathrm{p}<0.001)$. The skin manifestations seen in the patients with DM are illustrated in tables 2 and 3.

The most frequent manifestations were skin tags ( $\mathrm{n}=$ $131 ; 40.9 \%)$, cutaneous infections $(\mathrm{n}=123 ; 38.4 \%)$, xerosis $(n=118 ; 36.9 \%)$, paresthesia $(n=115 ; 35.9 \%)$, alopecialegs $(\mathrm{n}=112 ; 35 \%)$, Campbell de Morgan spots $(\mathrm{n}=98 ; 30.6 \%)$,

fungal infections ( $\mathrm{n}=90 ; 28.1 \%$ ), acquired ichthyosis $(n=72 ; 22.5 \%)$, hyperkeratosis feet $(n=60 ; 18.8 \%)$, seborrheic keratosis $(\mathrm{n}=41 ; 12.8 \%)$ and dry palms $(\mathrm{n}=38$; $11.9 \%$ ). The types of fungal, candidal, bacterial and viral infections are provided in table 4 . Tinea pedis (21.9\%) was the most common fungal infection and oropharyngeal candidiasis was the most common candidal infection, while cellulitis and folliculitis were the most common bacterial infections. Four patients had recurrent herpes simplex.

\section{Discussion}

A broad spectrum of cutaneous disorders may be encountered in patients with both type 1 and type $2 \mathrm{DM}$. The main mechanism for the skin changes seen in DM is thought to be nonenzymatic glycosylation product formation and changes in the physical and chemical properties of connective tissue and other body proteins. These modified proteins and glycosylation products are responsible for the change in color and texture of the skin and the various complications seen in DM [9-13].

The $91.2 \%$ of diabetic patients with cutaneous disorders are generally similar to previous reports of $30-90 \%$ $[3,6,14]$. Equally, male patients outnumbering female patients (table 1) had been reported in a previous study [15]. 
Table 1. Demographic data of study participants

\begin{tabular}{|c|c|c|c|c|c|}
\hline & \multirow[t]{2}{*}{ Total } & \multicolumn{2}{|c|}{ Type of DM } & \multicolumn{2}{|c|}{ Duration of DM } \\
\hline & & type 1 & type 2 & $\leq 5$ years & $>5$ years \\
\hline Number of patients & $320(100)$ & $35(10.9)$ & $285(89.1)$ & $124(38.8)$ & $196(61.2)$ \\
\hline \multicolumn{6}{|l|}{ Sex } \\
\hline Male & $174(54.4)$ & $16(45.7)$ & $158(55.4)$ & $76(61.3)$ & $98(50)$ \\
\hline Female & $146(45.6)$ & $19(54.3)$ & $127(44.6)$ & $48(38.7)$ & $98(50)$ \\
\hline \multicolumn{6}{|l|}{ Age, years } \\
\hline Range & $12-103$ & $12-55$ & $35-103$ & $12-95$ & $21-103$ \\
\hline Mean \pm SD & $57.43 \pm 16.22$ & $28.11 \pm 10.57$ & $61.03 \pm 12.78$ & $48.85 \pm 17.35$ & $62.86 \pm 12.81$ \\
\hline \multicolumn{6}{|l|}{ Age of onset, years } \\
\hline Range & $9-90$ & $9-35$ & $34-90$ & $9-90$ & $10-80$ \\
\hline Mean $\pm S D$ & $47.72 \pm 14.04$ & $22.4 \pm 6.8$ & $50.82 \pm 11.28$ & $46.53 \pm 17.36$ & $48.46 \pm 11.44$ \\
\hline \multicolumn{6}{|l|}{ Family history } \\
\hline Positive & $205(64)$ & $27(77.1)$ & $178(62.5)$ & $75(60.5)$ & $130(66.3)$ \\
\hline Negative & $115(36)$ & $8(22.9)$ & $107(37.5)$ & $49(39.5)$ & $66(33.7)$ \\
\hline \multicolumn{6}{|l|}{ Patients with skin } \\
\hline manifestations & $292(91.2)$ & $12(34.3)^{*}$ & $280(98.2)$ & $100(80.6)^{*}$ & $192(98)$ \\
\hline
\end{tabular}

Values in parentheses denote percentages. ${ }^{*} \mathrm{p}<0.001$.

Table 2. Skin manifestations seen in patients with DM

\begin{tabular}{|c|c|c|c|c|}
\hline & \multirow[t]{2}{*}{ Total } & \multicolumn{3}{|c|}{ Duration of DM } \\
\hline & & $\leq 5$ years & $>5$ years & $\mathrm{p}$ \\
\hline \multicolumn{5}{|l|}{ Vascular manifestations } \\
\hline Gangrene & $23(7.2)$ & $1(0.3)$ & $22(6.9)$ & 0.0001 \\
\hline Palmar erythema & $17(5.3)$ & $9(2.8)$ & $8(2.5)$ & NS \\
\hline Diabetic dermopathy & $13(4.1)$ & $1(0.3)$ & $12(3.8)$ & 0.014 \\
\hline Rubeosis faciei & $10(3.1)$ & $4(1.3)$ & $6(1.9)$ & NS \\
\hline Sclerosis fingers & $3(0.9)$ & - & $3(0.9)$ & NS \\
\hline Periungual telangiectasia & $3(0.9)$ & $3(0.9)$ & - & NS \\
\hline Pigmented purpuric dermatosis & $3(0.9)$ & - & $3(0.9)$ & NS \\
\hline Ecchymosis & $2(0.6)$ & - & $2(0.6)$ & NS \\
\hline Diabetic hands & $2(0.6)$ & $1(0.3)$ & $1(0.3)$ & NS \\
\hline Granuloma annulare & $1(0.3)$ & - & $1(0.3)$ & NS \\
\hline \multicolumn{5}{|l|}{ Neurological manifestations } \\
\hline Paresthesia & $115(35.9)$ & $20(6.2)$ & $95(29.7)$ & 0.0001 \\
\hline Diabetic feet & $23(7.2)$ & $1(0.3)$ & $22(6.9)$ & 0.0001 \\
\hline Diabetic bullae & $7(2.2)$ & - & $7(2.2)$ & 0.031 \\
\hline Generalized hyperhidrosis & $2(0.6)$ & $1(0.3)$ & $1(0.3)$ & NS \\
\hline Hyperhidrosis face & $1(0.3)$ & - & $1(0.3)$ & NS \\
\hline \multicolumn{5}{|l|}{ Therapy complications } \\
\hline Chronic urticaria & $4(1.3)$ & $1(0.3)$ & $3(0.9)$ & NS \\
\hline Lipodystrophy & $3(0.9)$ & - & $3(0.9)$ & NS \\
\hline Painful indurations & $3(0.9)$ & $2(0.6)$ & $1(0.3)$ & NS \\
\hline Pigmentation at insulin injection sites & $3(0.9)$ & - & $3(0.9)$ & NS \\
\hline
\end{tabular}

Values in parentheses denote percentages. NS = Not significant. 
Table 3. Miscellaneous skin manifestations seen in patients with DM

\begin{tabular}{|c|c|c|c|c|}
\hline & \multirow[t]{2}{*}{ Total } & \multicolumn{3}{|c|}{ Duration of DM } \\
\hline & & $\leq 5$ years & $>5$ years & $\mathrm{p}$ \\
\hline Skin tags & $131(40.9)$ & $52(16.2)$ & $79(24.7)$ & NS \\
\hline Xerosis & $118(36.9)$ & $44(13.8)$ & $74(23.1)$ & NS \\
\hline Alopecia legs & $112(35.0)$ & $43(13.4)$ & $69(21.6)$ & NS \\
\hline \multicolumn{5}{|l|}{ Campbell de Morgan } \\
\hline spots & $98(30.6)$ & $34(10.6)$ & $64(20.0)$ & NS \\
\hline Acquired ichthyosis & $72(22.5)$ & $22(6.9)$ & $50(15.6)$ & NS \\
\hline Hyperkeratosis feet & $60(18.7)$ & $19(5.9)$ & $41(12.8)$ & NS \\
\hline Seborrheic keratosis & $41(12.8)$ & $17(5.3)$ & $24(7.5)$ & NS \\
\hline Dry palms & $38(11.9)$ & $14(4.4)$ & $24(7.5)$ & NS \\
\hline Generalized pruritus & $22(6.9)$ & $6(1.9)$ & $16(5.0)$ & NS \\
\hline Callosities & $19(5.9)$ & $8(2.5)$ & $11(3.4)$ & NS \\
\hline Chronic eczema & $13(4.1)$ & $6(1.9)$ & $7(2.2)$ & NS \\
\hline Koilonychia & $12(3.8)$ & $4(1.3)$ & $8(2.5)$ & NS \\
\hline Intertrigo & $11(3.4)$ & $4(1.3)$ & $7(2.2)$ & NS \\
\hline Yellow palms & $9(2.8)$ & $1(0.3)$ & $8(2.5)$ & NS \\
\hline Acanthosis nigricans & $8(2.5)$ & $5(1.6)$ & $3(0.9)$ & NS \\
\hline \multicolumn{5}{|l|}{ Dupuytren's } \\
\hline contracture & $6(1.9)$ & - & $6(1.9)$ & NS \\
\hline Yellow nails & $3(0.9)$ & - & $3(0.9)$ & NS \\
\hline Pruritus vulvae & $3(0.9)$ & - & $3(0.9)$ & NS \\
\hline Scleredema of diabetes & $3(0.9)$ & $1(0.3)$ & $2(0.6)$ & NS \\
\hline Finger pebbles & $2(0.6)$ & $1(0.3)$ & $1(0.3)$ & NS \\
\hline Eruptive xanthomas & $2(0.6)$ & - & $2(0.6)$ & NS \\
\hline \multicolumn{5}{|l|}{ Acquired perforating } \\
\hline dermatoses & $2(0.6)$ & - & $2(0.6)$ & NS \\
\hline
\end{tabular}

Values in parentheses denote percentages. NS = Not significant.

The majority of patients (98.2\%) in this study had type 2 $\mathrm{DM}$, as has been noted in other studies [16, 17], apparently reflecting the general distribution pattern of type 1 and type $2 \mathrm{DM}$ cases in world populations $[7,15]$. There was a statistically significant $(\mathrm{p}<0.001)$ difference in skin manifestations between our type 1 and type $2 \mathrm{DM}$ patients, contrary to the finding in other studies $[7,15,17]$. Most of the patients (71\%) with type 1 diabetes in our study had a brief duration of diabetes (group I). This may be the reason for the lower prevalence of skin disorders in our type 1 diabetic patients.

There was a statistically significant $(\mathrm{p}<0.001)$ difference in skin manifestations among the 2 duration groups in our study, a finding which is contrary to the finding by Mahmood et al.. In our study, $80.6 \%$ of the patients having diabetes of up to 5 years' duration had skin manifestations compared to $98 \%$ of those with diabetes of more than 5 years' duration. In the study done by Mahmood et
Table 4. Types of infection seen among diabetic patients

\begin{tabular}{lrlrl}
\hline & Total & \multicolumn{2}{l}{ Duration of DM } \\
\cline { 3 - 5 } & & $\leq 5$ years & $>5$ years & p \\
\hline Cutaneous infections & $123(38.4)$ & $37(11.5)$ & $86(26.9)$ & 0.008 \\
Fungal infections & $90(28.1)$ & $27(8.4)$ & $63(19.7)$ & 0.029 \\
Tinea pedis & $70(21.9)$ & $23(7.2)$ & $47(14.7)$ & NS \\
Onychomycosis & $17(5.3)$ & $3(0.9)$ & $14(4.4)$ & NS \\
Tinea corporis & $3(0.9)$ & $1(0.3)$ & $2(0.6)$ & NS \\
Candidal infections & $16(5.0)$ & $3(0.9)$ & $13(4.1)$ & NS \\
Oropharyngeal & $8(2.5)$ & $3(0.9)$ & $5(1.6)$ & NS \\
Angular cheilitis & $4(1.3)$ & $1(0.3)$ & $3(0.9)$ & NS \\
Interdigital & $3(0.9)$ & - & $3(0.9)$ & NS \\
Genital & $2(0.6)$ & - & $2(0.6)$ & NS \\
Bacterial infections & $16(5.0)$ & $6(1.9)$ & $10(3.1)$ & NS \\
Cellulitis & $6(1.9)$ & - & $6(1.9)$ & NS \\
Folliculitis & $5(1.6)$ & $3(0.9)$ & $2(0.6)$ & NS \\
Furunculosis & $4(1.3)$ & $3(0.9)$ & $1(0.3)$ & NS \\
Erythrasma & $1(0.3)$ & - & $1(0.3)$ & NS \\
Viral infections & $9(2.8)$ & $3(0.9)$ & $6(1.9)$ & NS \\
Herpes simplex & $4(1.3)$ & $3(0.9)$ & $1(0.3)$ & NS \\
Warts & $3(0.9)$ & $1(0.3)$ & $2(0.6)$ & NS \\
Herpes zoster & $2(0.6)$ & - & $2(0.6)$ & NS \\
\hline
\end{tabular}

Values in parentheses denote percentages. NS = Not significant.

al. [3], patients with diabetes of 5 years' duration had an $80 \%$ prevalence of skin manifestations, while in patients with diabetes of more than 5 years' duration, the prevalence of skin manifestations was $81.5 \%$. The skin manifestations that had a statistically significant $(\mathrm{p}<0.05)$ difference in prevalence between our 2 duration groups are gangrene, diabetic dermopathy, paresthesia, diabetic feet, diabetic bullae and fungal infections (tables 2, 4). Our study shows that as the duration of diabetes increased, the chances of developing skin manifestations also increased. Since more than $80 \%$ of the patients in group I developed skin manifestations within 5 years' duration, it signified the importance of early dermatological examination in diabetic patients to detect skin complications of DM at an early stage for the prevention of disability caused by these complications.

Among the skin manifestations observed in our diabetic patients, $40.9 \%$ were skin tags, similar to the finding by Margolis and Margolis [18], thus revealing the importance of evaluation of diabetes in patients with multiple skin tags. Cutaneous infections (38.4\%) comprised the second most frequent manifestation seen in our patients, similar to previous reports [14, 17]. Fungal infections (28.1\%) were among the most frequent cutaneous infec- 
tions, and tinea pedis (21.9\%) was most frequent among fungal infections, a finding similar to that of a previous study [19]. Among cutaneous infections, bacterial, candidal and viral infections were also seen in our study group, but they were fewer than in a study done by Al-Mutairi et al. [17], although viral warts and herpes zoster cases were seen in our patients but not in their study [17].

Skin manifestations due to diabetic complications were frequently observed. In accordance with the previous reports $[3,14,20]$, paresthesia due to peripheral neuropathy was found in $35.9 \%$ of our patients. In our study, diabetic foot secondary to neuropathy, vasculopathy and poor wound healing was seen in a higher percentage of patients (7.2\%) compared to the $2.9 \%$ in the patients of Mahmood et al. [3]. There was an incidence of cutaneous markers of DM, e.g. acanthosis nigricans, in our study, but necrobiosis lipoidica diabeticorum was not observed as reported in other studies [3, 17]. Skin reactions like chronic urticaria, lipodystrophy, painful indurations and pigmentation at insulin injection sites arising from diabetic treatment (oral hypoglycemics and insulin) occurred in our study, in agreement with other studies [3, 17].

Among other frequent manifestations, there was a higher percentage of xerosis (36.9\%), alopecia legs (35\%), Campbell de Morgan spots (30.6\%), hyperkeratosis feet (18.7\%), seborrheic keratosis (12.8\%) and dry palms (11.9\%) in our study. There was an equal percentage of acquired ichthyosis (22.5\%) compared to the results by Mahmood et al. [3]. Among the common findings of our study, generalized pruritus, callosities and palmar erythema also occurred in other studies with variable percentages. However, gangrene was not seen in the study done by Mahmood et al. [3]. Some of the less common manifestations that occurred in our study, including chronic eczema, diabetic dermopathy, rubeosis faciei, koilonychia, intertrigo, sclerosis fingers, periungual telangiectasia, pigmented purpuric dermatosis, generalized hyperhidrosis, hyperhidrosis face, yellow palms, Dupuytren's contracture, yellow nails, pruritus vulvae, scleredema of diabetes, finger pebbles, eruptive xanthomas and acquired perforating dermatoses, have also been described previously $[3,17]$.

\section{Conclusion}

The prevalence of skin manifestations was higher in type 2 than in type 1 diabetic patients, and as the duration of diabetes increased, the likelihood of developing skin manifestations also increased. Early referral to the dermatologist may help detect skin complications of diabetes at an early stage to prevent disability caused by these complications.

\section{References}

$\checkmark 1$ Perez MI, Kohn SR: Cutaneous manifestations of diabetes mellitus. J Am Acad Dermatol 1994;30:519-531.

$>2$ Wahid Z, Kanjee A: Cutaneous manifestations of diabetes mellitus. J Pak Med Assoc 1998;48:304-305.

3 Mahmood T, Bari A, Agha H: Cutaneous manifestations of diabetes mellitus. J Pak Assoc Dermatol 2005;15:227-232.

4 Oumeish OY: Skin disorders in patients with diabetes. Clin Dermatol 2008;26:235-242.

5 Ahmed I, Goldstein B: Diabetes mellitus. Clin Dermatol 2006;24:237-246.

-6 Romano G, Moretti G, di Benedetto: Skin lesions in diabetes mellitus: prevalence and clinical correlations. Diabetes Res Clin Pract 1998;39:101-106.

7 Paron NG, Lambert PW: Cutaneous manifestations of diabetes mellitus. Prim Care 2000;27:371-383.

$\checkmark$ Pavlović MD, Milenković T, Dinić M, Misović M, Daković D, Todorović S, Daković Z, Zecevi RD, Doder R: The prevalence of cutaneous manifestations in young patients with type 1 diabetes. Diabetes Care 2007;30: 1964-1967.
-9 Schneider JB, Norman RA: Cutaneous manifestations of endocrine-metabolic disease and nutritional deficiency in the elderly. Dermatol Clin 2004;22:23-31.

10 van Hattem S, Bootsma AH, Thio HB: Skin manifestations of diabetes. Cleve Clin J Med 2008;75:772-787.

11 Rich P: Nail changes due to diabetes and other endocrinopathies. Dermatol Ther 2002; 15:107-110.

12 Wautier JL, Guillausseau PJ: Advanced glycation end products, their receptors and diabetic angiopathy. Diabetes Metab 2001;27: 535-542.

13 Ferringer T, Miller F 3rd: Cutaneous manifestations of diabetes mellitus. Dermatol Clin 2002;20:483-492.

14 Naheed T, Akbar N, Akbar N, Shehzad M, Jamil S, Ali T: Skin manifestations amongst diabetic patients admitted in a general medical ward for various other medical problems. Pak J Med Sci 2002;18:291-296.
15 Nigam PK, Pande S: Pattern of dermatoses in diabetics. Indian J Dermatol Venereol Leprol 2003;69:83-85.

16 Mahajan S, Koranne RV, Sharma SK: Cutaneous manifestation of diabetes mellitus. Indian J Dermatol Venereol Leprol 2003;69: 105-108

$>17$ Al-Mutairi N, Zaki A, Sharma AK, Al-Sheltawi M: Cutaneous manifestations of diabetes mellitus. Med Princ Pract 2006;15:427430

18 Margolis J, Margolis LS: Skin tags: a frequent sign of diabetes mellitus. N Engl J Med 1976; 294:1184.

-19 Eckhard M, Lengler A, Liersch J, Bretzel RG, Mayser P: Fungal foot infections in patients with diabetes mellitus: results of two independent investigations. Mycoses 2007;50 (suppl 2):14-19.

20 Shun CT, Chang YC, Wu HP, Hsieh SC, Lin WM, Lin YH, Tai TY, Hsieh ST: Skin denervation in type 2 diabetes: correlations with diabetic duration and functional impairments. Brain 2004;127:1593-1605. 